\title{
Safety and efficacy of a novel retrograde route for femoral bone graft harvesting by Reamer-Irrigator-Aspirator: a pilot study on 24 patients
}

\author{
Fernando Bidolegui ${ }^{1}$, Sebastián Pereira ${ }^{1}$, Cristina Irigoyen $^{1}$ and Robinson Esteves Pires ${ }^{2,3^{*}}$ (1)
}

\begin{abstract}
Background: The Reamer-Irrigator-Aspirator system was initially developed to reduce fat embolism and thermic necrosis during reamed intramedullary nail fixation of femoral shaft fractures. Currently, this system is used in extended applications including accessing large volume of autologous bone graft, as alternative for iliac crest harvesting. Antegrade femoral bone graft harvesting using the Reamer-Irrigator-Aspirator system is considered the standard technique. The aim of our study is to evaluate the efficacy (bone graft volume) and the complications (blood loss, postoperative pain, and incidence of iatrogenic fractures) of the Reamer-Irrigator-Aspirator system through the retrograde femoral route in a series of patients with post-traumatic bone defects or nonunions.
\end{abstract}

Methods: A non-controlled single center retrospective observational cohort study was conducted in a level1 trauma center to evaluate all patients who were treated using the RIA system. Between November 2015 and May 2019, 24 patients ( 8 women and 16 men; mean age: 41 years [range $27-55$ years]) with bone defects or nonunions underwent bone graft harvesting using the Reamer-Irrigator-Aspirator system through retrograde femoral route. Postoperative pain, complications, and bone graft volume were analyzed. Inclusion criteria was patients older than 18 years with a diagnosis of post-traumatic bone defect or associated tibial or femoral nonunion, with minimum 6-months follow, treated using the RIA. We hypothesized that the retrograde route of the RIA system is a safe and efficacious method for bone harvesting.

Results: The average volume of collected graft was $45 \mathrm{cc}$ (range 30-60 cc). In 83\% of the cases, bone grafting was sufficient, while in $17 \%$ it was necessary to add iliac crest bone graft to completely fill the bone defect. A mean drop in postoperative hemoglobin of $4.1 \mathrm{~g} / \mathrm{dL}$ (range 0.5-6.0 g / dL) was evidenced. In 4 cases (33\%), a unit of packed red blood cells was required. Regarding postoperative pain, visual analogue scale after 3 months postoperatively was 1.6 in average. After 6 months, the value has decreased to 0.4. There were no perioperative or postoperative complications at 6-month follow-up.

Conclusion: In this limited case series, large volumes of bone graft were harvested using the retrograde route of the RIA system and there were no intra-/ postoperative complications observed at 6-month follow-up. Therefore this novel technique appears safe and efficacious.

\footnotetext{
*Correspondence: robinsonestevespires@gmail.com

${ }^{2}$ Departamento Do Aparelho Locomotor, Universidade Federal de Minas Gerais, Belo Horizonte, MG, Brazil
}

Full list of author information is available at the end of the article permits use, sharing, adaptation, distribution and reproduction in any medium or format, as long as you give appropriate credit to the original author(s) and the source, provide a link to the Creative Commons licence, and indicate if changes were made. The images or other third party material in this article are included in the article's Creative Commons licence, unless indicated otherwise in a credit line to the material. If material is not included in the article's Creative Commons licence and your intended use is not permitted by statutory regulation or exceeds the permitted use, you will need to obtain permission directly from the copyright holder. To view a copy of this licence, visit http://creativecommons.org/licenses/by/4.0/. The Creative Commons Public Domain Dedication waiver (http://creativeco mmons.org/publicdomain/zero/1.0/) applies to the data made available in this article, unless otherwise stated in a credit line to the data. 
However, it's important to highlight that future prospective controlled studies are necessary to validate the insights from this pilot study.

Keywords: Reamer-Irrigator-Aspirator, Bone graft, Bone defects, Osteomyelitis, Patient safety

\section{Introduction}

The Reamer-Irrigator-Aspirator (RIA; Synthes, West Chester, PA), initially developed to decrease thermal necrosis and the incidence of fat embolism during diaphyseal femur reaming, is also routinely used for the treatment of long bone osteomyelitis, since it removes infected and necrotic bone from the medullary canal. However, especially in the last decade, it has become a helpful alternative to the classic iliac crest bone graft harvesting, since it offers a larger volume of bone graft without the drawback of severe postoperative pain, which frequently accompanies the iliac crest bone graft harvesting [1-4]. Extended applications of the RIA system are clearing the femoral/tibial canal of cement debris and intramedullary nailing of long bones with metastatic diseases, since it potentially diminishes the tumor burden into the surrounding soft tissues and systemic circulation [5].

The standard donor site for the RIA system is the femur, mostly using the antegrade pathway [3].

Although a previous study comparing antegrade and retrograde techniques using the RIA system have shown similar morbidity and amount of bone graft harvested, a special concern exists when using the antegrade pathway due to the risk of eccentric reaming, potentially predisposing to an iatrogenic fracture [6].

Thus, the aim of this study was to evaluate the efficacy (bone graft volume) and safety (blood loss, postoperative pain, and incidence of iatrogenic fracture) of the RIA system through the retrograde route in a case series of patients with bone defects.

\section{Methods}

A non-controlled single center retrospective observational cohort study was conducted in a level 1 trauma center to evaluate all patients who were treated using the RIA system between November 2015 and May 2019. The digitized medical records of the institution were used for data collection. All patients older than 18 years with a diagnosis of post-traumatic bone defect or associated tibial or femoral nonunion, with minimum 6-months follow, were included.

Figure 1 shows the retrograde portal for bone graft harvesting using the RIA system (Fig. 1). Those patients in whom the RIA system was used through an antegrade route in the femur (n:2) or tibia (n: 1) and those who did not comply with the minimum follow-up (n: 1) were excluded.
The series consisted of 24 patients ( 8 women and 16 men). The mean age was 41 years (range $27-55$ years). The diagnoses were: 10 aseptic nonunions of the femur (42\%), 2 septic nonunions of the femur (8\%), 6 aseptic nonunions of the tibia (25\%), 4 septic nonunions of the tibia (17\%), and 2 acute post-traumatic femoral bone defects $(8 \%)$. The cases that were diagnosed with septic nonunion were treated initially with the modified Masquelet technique. The first procedure was debridement and resection of the infected bone, filling the bone defect with cement impregnated with antibiotics (2-4 g of Vancomycin per cement pack). Intravenous antibiotics was administered according to the results of culture. Once the infectious process was controlled, the RIA technique was performed to fill the bone defect.

The volume of the collected graft was measured, as well as the evaluation of postoperative transfusion rate, postoperative pain, and complications (Table 1).

To determine the appropriate size of the reamer, the diameter of the isthmus in the anteroposterior view was measured with a ruler provided by the manufacturer of the RIA system, under fluoroscopy. The reamer diameter was $1.5 \mathrm{~mm}$ diameter larger than the isthmus measurement. The volume of collected bone graft was measured in $20 \mathrm{cc}$ syringes (Figs. 2 and 3). At $24 \mathrm{~h}$ postoperatively, hemoglobin levels were compared with the preoperative levels. Patients requiring a blood transfusion were registered. The transfusion criteria were: symptomatic patients, hemoglobin less than $8 \mathrm{~g} / \mathrm{dl}$ or $9 \mathrm{~g} / \mathrm{dl}$, in patients with a cardiac history. Regarding postoperative pain, the patients were evaluated at 3 and 6 months. At each

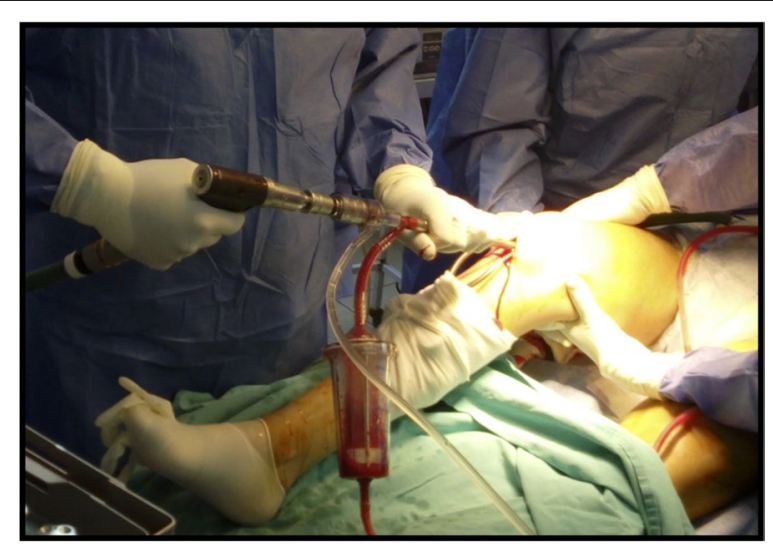

Fig. 1 Intraoperative photograph depicting the retrograde pathway for bone graft harvesting using the RIA system 
Table 1 Pre- and postoperative patient data

\begin{tabular}{|c|c|c|c|c|c|c|c|c|}
\hline Gender & Age & Diagnosis & Transfusion & Preop $\mathrm{Hb}$ & Postop Hb & $\begin{array}{l}\text { VAS } \\
3 \text { months }\end{array}$ & $\begin{array}{l}\text { VAS } \\
6 \text { months }\end{array}$ & Graft vol (cc) \\
\hline $\mathrm{F}$ & 27 & Aseptic nonunion left femur & Not & 14,6 & 10,1 & 2 & 1 & 50 \\
\hline M & 34 & Aseptic nonunion left femur & $\begin{array}{l}1 \text { unit of PRBC }+2 \\
\text { units of plasma }\end{array}$ & 12,6 & 7,1 & 2 & 0 & 40 \\
\hline M & 49 & Aseptic nonunion left femur & Not & 13,3 & 9,3 & 1 & 0 & 55 \\
\hline M & 50 & Aseptic nonunion right femur & 1 unit of PRBC & 12,9 & 7,2 & 1 & 0 & 55 \\
\hline M & 27 & Infected nonunion left tibia & 1 unit of PRBC & 14,1 & 7,5 & 1 & 0 & 35 \\
\hline M & 30 & Infected nonunion left tibia & Not & 14,9 & 9,6 & 1 & 0 & 60 \\
\hline $\mathrm{F}$ & 27 & Infected nonunion right femur & Not & 13,6 & 10,4 & 1 & 0 & 55 \\
\hline M & 47 & Infected nonunion left tibia & Not & 14,7 & 11,3 & 2 & 1 & 50 \\
\hline M & 41 & Aseptic nonunion right tibia & Not & 13,0 & 10,4 & 1 & 0 & $45+$ \\
\hline M & 33 & Aseptic nonunion right femur & Not & 14,3 & 9,7 & 3 & 1 & 50 \\
\hline $\mathrm{F}$ & 55 & Infected nonunion left tibia & 1 unit of PRBC & 11,2 & 7,2 & 1 & 1 & 30 \\
\hline $\mathrm{F}$ & 27 & Infected nonunion right femur & Not & 14,1 & 9,4 & 2 & 0 & 50 \\
\hline $\mathrm{F}$ & 34 & Aseptic nonunion left tibia & Not & 12,5 & 10,4 & 1 & 0 & 40 \\
\hline $\mathrm{F}$ & 49 & Aseptic nonunion left femur & Not & 12,6 & 9,6 & 1 & 0 & 45 \\
\hline $\mathrm{F}$ & 55 & Aseptic nonunion left femur & Not & 13,2 & 10,1 & 1 & 0 & $40+$ \\
\hline M & 34 & Aseptic nonunion left femur & Not & 14,2 & 9,8 & 1 & 1 & 60 \\
\hline M & 30 & Aseptic nonunion right tibia & Not & 12,3 & 8,3 & 3 & 1 & 50 \\
\hline M & 27 & Open fracture left femur & Not & 14,2 & 9,4 & 2 & 0 & 45 \\
\hline M & 47 & Aseptic nonunion left femur & Not & 14,7 & 10,1 & 2 & 1 & 40 \\
\hline M & 41 & Aseptic nonunion left femur & Not & 13,1 & 9,3 & 4 & 2 & 50 \\
\hline M & 36 & Aseptic nonunion left femur & Not & 13,7 & 10,4 & 2 & 0 & 45 \\
\hline M & 44 & Aseptic nonunion right tibia & Not & 12,5 & 9,8 & 1 & 0 & 40 \\
\hline M & 27 & Aseptic nonunion left tibia & Not & 14,3 & 9,5 & 1 & 0 & 55 \\
\hline $\mathrm{F}$ & 34 & Open fracture left femur & Not & 13,2 & 8,8 & 2 & 1 & 60 \\
\hline
\end{tabular}

+ ICBG (iliac crest bone graft) PRBC Packed red blood cells

$F$ Female, $M$ Male

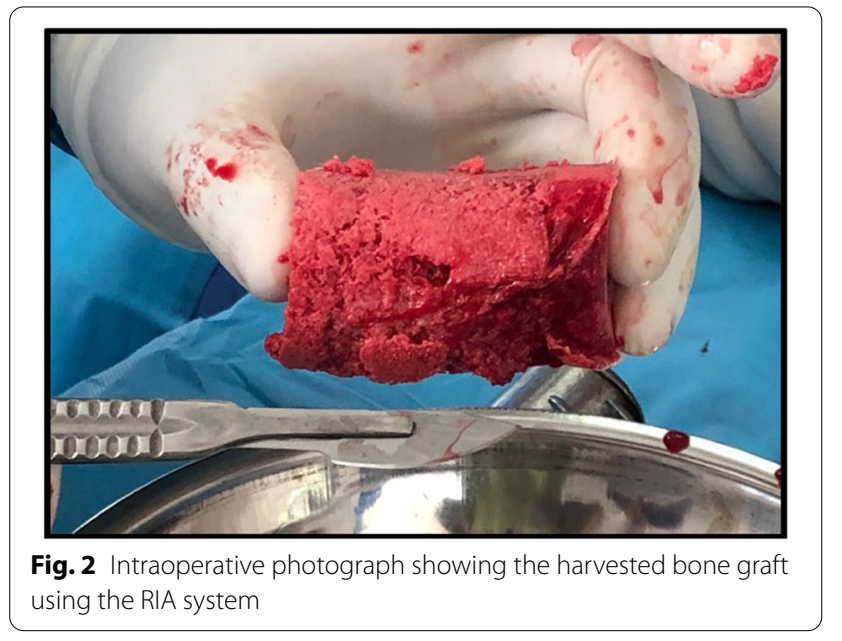

visit, the presence or absence of pain was documented using the Visual Analogue Pain Scale (VAS). The present study was approved by the ethics committee of the main institution.

\section{Results}

The bone graft volume was $45 \mathrm{cc}$ on average (range $30-60 \mathrm{cc}$ ). In 10 patients (83\%), bone grafting by RIA was sufficient to fill the bone defect, while in 2 cases (17\%) it was necessary to add autologous iliac crest bone graft to completely fill the bone defect. A mean drop in postoperative hemoglobin of $4.1 \mathrm{~g} / \mathrm{dL}$ (range $0.5-6.0 \mathrm{~g} / \mathrm{dL}$ ) was evidenced. In 4 cases (33\%), a unit of packed red blood cells was required. Regarding postoperative knee pain, average VAS at 3 months was (1.6) and (0.4) at 6 months. No patients reported persistent and significant donor site pain at the time of the last follow-up. No cases of intraor postoperative femoral fracture were observed. 


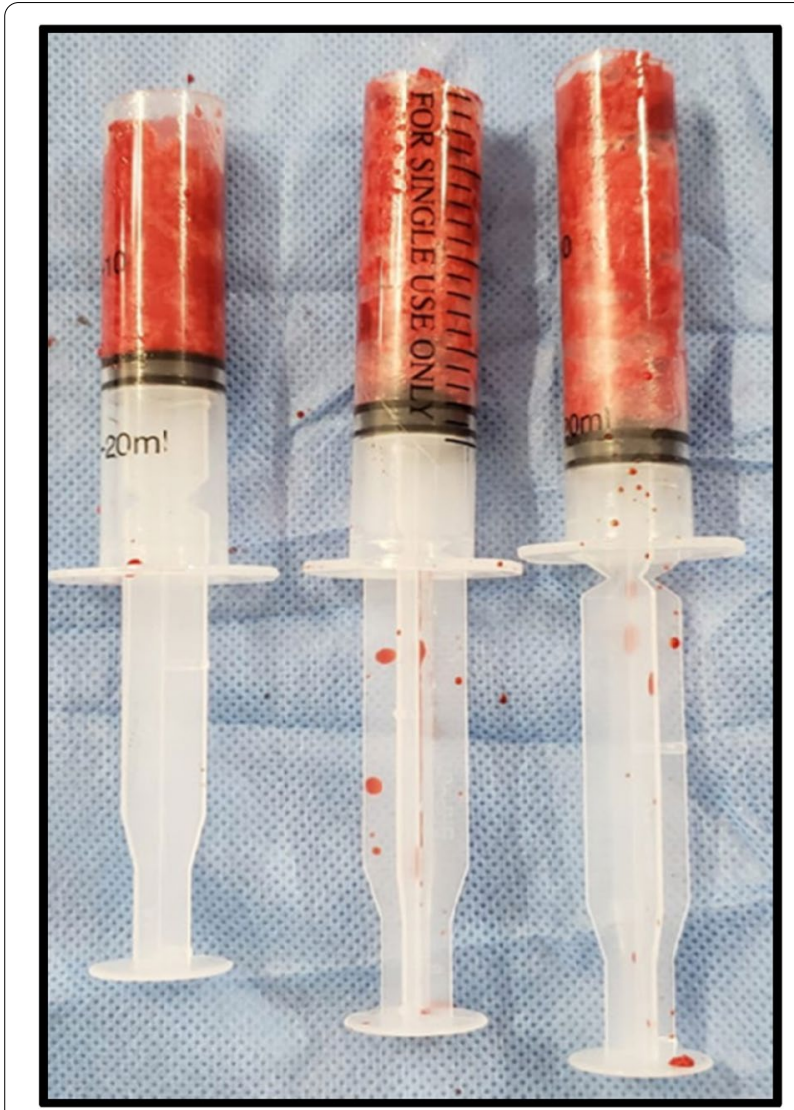

Fig. 3 Measurement of the volume of the harvested bone graft using 20 cc syringes

However, we detected uneccentric reaming in the postoperative radiograph of one patient. In this case, since the femur was ipsilateral to the tibial bone defect, the patient was not allowed to weight bearing until the 12th postoperative week. There were no additional postoperative complications such as infection, heterotopic ossification, and thromboembolic events.

\section{Discussion}

The advantageous biological properties of the harvested bone graft, besides the amount of volume obtained, ratify the RIA system as a safe and efficient alternative to the traditional iliac crest bone grafting [1-5].

Kanakaris et al. reported an average bone graft volume using the RIA system of $65 \mathrm{cc}$ (range 40 to $85 \mathrm{cc}$ ) [7]. McCall et al. reported an average volume of $64 \mathrm{ml}$, being $67 \mathrm{cc}$ from the femur and $37.5 \mathrm{cc}$ from the tibia. The authors highlighted that collected bone graft was not the maximum available volume, since patients with smaller defects needed less bone graft [8]. These results are also comparable with those presented by Han et al., who obtained an average volume of $40.6 \mathrm{cc}$ (range 20 to
$80 \mathrm{cc}$ [ [9]. In our series, the average volume collected was $45 \mathrm{cc}$ (range 30 to $60 \mathrm{cc}$ ). In 10 of the 12 cases, the volume obtained was sufficient to fill the defect, while in the remaining two cases it was supplemented with an autologous iliac crest graft. On the other hand, Stafford et al. present an average volume of $47 \mathrm{cc}$, requiring the use of complementary material in 23 of their 27 cases [10].

The biological properties of the bone graft using the RIA system were extensively reported on the literature $[11,12]$. Sagi et al. evaluated the quantitative and qualitative differences of the bone graft obtained from the medullary canal and the iliac crest, showing that the graft obtained from the iliac crest has clear disadvantages in terms of the morbidity of the donor site and the limited volume obtained. The authors pointed out that the RIA samples had a higher number of mesenchymal stem cells than the iliac crest bone graft, and would also have greater regenerative characteristics [13].

El-Jawhari et al. evaluated the biological fitness of bone progenitor cells in RIA waste. The authors found that the RIA-W bag, which is generally wasted in routine practice may offer great clinical value as an abundant source of functionally competent bone progenitor cells [14].

Due to the possibility of generating eccentric or excessive reaming of the canal during the RIA technique, iatrogenic femoral fractures were previously reported on the literature $[6,9,15]$. Han et al. evaluated 57 patients treated using the RIA system and reported a femoral fracture at the graft harvesting site that required fixation with an intramedullary nail [9]. Belthur et al. also described 2 cases of perforations of the anterior cortex of the femur among their 41 patients treated with RIA [15]. Davis et al., comparing retrograde versus antegrade route using the RIA system in the femur, reported a significant increase in the risk of an iatrogenic fracture of the femur with the antegrade route [6]. Although we detected uneccentric reaming in the postoperative radiograph of one of our patients, there was no postoperative femoral fracture until the last follow-up. Schmitz et al., in a biomechanical cadaveric study, evaluated the influence of the ReamerIrrigator-Aspirator diameter on femoral bone strength and amount of harvested bone graft. The authors concluded that reaming with RIA diameter of $4.0 \mathrm{~mm}$ larger than the femoral isthmus may considerably influence its torsional stiffness, thereby increasing the risk of iatrogenic fracture [16].

Due to the abundant intramedullary blood supply, the presence of hemorrhage is another possible complication when using the RIA technique $[1,2,17]$. During conventional reaming, $100 \mathrm{cc}$ of blood loss may be found [1]. Prolonged suction and aspiration using the RIA system may enhance the blood loss. Han et al. described that 7 of their 57 patients required transfusion after surgery due 
to a mean drop in hemoglobin of $3.15 \mathrm{~g} / \mathrm{dl}$ [9]. Marchand et al. conducted a comparative study between the RIA system and the iliac crest autologous bone graft technique and analyzed the estimated amount of blood loss as well as the percentages of blood transfusion. They reported an average loss of $674 \mathrm{cc}$ in the RIA group vs $255 \mathrm{cc}$ in the iliac crest graft group. At the same time, $44 \%$ of the patients in the RIA group required a blood transfusion vs $21 \%$ in the iliac crest bone graft group [18]. Although in our series we did not directly measure the volume of blood loss, indirectly the average drop in hemoglobin $(4.1 \mathrm{~g} / \mathrm{dl})$ and the transfusion percentage of $33 \%$ are in line with those reported series and highlight the importance of predicting this possibility.

Regarding postoperative pain in the donor area, different studies highlighted lower morbidity associated with RIA compared to autologous iliac crest graft. Belthur et al. conducted a comparative study of patients treated using RIA technique (41 cases) and patients treated with iliac crest bone graft (40 cases), in which a reduction in postoperative pain was found in patients treated with RIA [15]. Davis et al., in his analysis of postoperative pain after the use of the RIA according to the access route, reported greater knee pain in the retrograde group vs greater hip pain in the antegrade group. However, at the end of follow-up, none of the patients manifested discomfort or persistent pain around the knee or the hip. Corroborating with previous reports, we found no persistent pain at the final follow-up in any of the patients.

The study imitations include the retrospective observational study design, the selection bias related to the inclusion criteria, the lack of a control group with the antegrade route and with the traditional technique of autologous bone grafting from the iliac crest, and lack of long-term follow-up to evaluate knee pain, septic arthritis, hemarthrosis, and other complications related to the retrograde approach.

\section{Conclusion}

In this limited case series, the use of the RIA system through a retrograde route in the femur allowed to obtain large volumes of bone graft. There were no intra-/ postoperative complications observed at 6-month follow-up. Therefore this novel technique appears safe and efficacious. Further studies with large sample and prospective design comparing the antegrade and the retrograde pathways for bone grafting using the RIA system are required to fully validate the insights from this pilot study.

\section{Abbreviations}

RIA: Reamer-Irrigator-Aspirator; VAS: Visual Analogue Pain Scale; PRBC: Packed red blood cells; ICBG: Iliac crest bone graft.
Acknowledgements

Not applicable

\section{Authors' contributions}

$\mathrm{FB}, \mathrm{SP}, \mathrm{Cl}$, and REP had substantial contributions to the conception of the work, acquisition of data, literature review, and drafting the article. FB and SP preformed the surgical procedures. All authors revised the draft critically for important intellectual content. All authors read and approved the final manuscript.

\section{Funding}

No funding was involved to support this study.

\section{Availability of data and materials}

The datasets used and/or analyzed during the current study are available from the corresponding author on reasonable request.

\section{Declarations}

Ethics approval and consent to participate

Ethical approval was obtained by the ethics committee of the main institution. The manuscript contains no individual personal data. No consent for publication was necessary.

\section{Competing interests}

The authors declare that there are no monetary or other conflicts of interest related to the RIA product and the manufacturer of the device investigated in this study (DePuy-Synthes).

\section{Author details}

${ }^{1}$ Servicio de Ortopedia Y Traumatología, Hospital Sirio-Libanes, ECICARO, Ciudad Autónoma de Buenos Aires, Argentina. ${ }^{2}$ Departamento Do Aparelho Locomotor, Universidade Federal de Minas Gerais, Belo Horizonte, MG, Brazil. ${ }^{3}$ Serviço de Ortopedia ETraumatologia, Instituto Orizonti, Belo Horizonte, MG, Brazil.

Received: 9 March 2021 Accepted: 14 December 2021

Published online: 07 January 2022

\section{References}

1. Cox G, Jones E, McGonagle D, Giannoudis PV. Reamer-irrigator-aspirator indications and clinical results: a systematic review. Int Orthop. 2011;35(7):951-6. https://doi.org/10.1007/s00264-010-1189-z.

2. Giannoudis PV, Tzioupis C, Green J. Surgical techniques: how I do it? The Reamer/Irrigator/Aspirator (RIA) System. Injury. 2009;40(11):1231-6. https://doi.org/10.1016/j.injury.2009.07.070.

3. Newman JT, Stahel PF, Smith WR, Resende GV, Hak DJ, Morgan SJ. A new minimally invasive technique for large volume bone graft harvest for treatment of fracture nonunions. Orthopedics. 2008;31(3):257-61.

4. Metsemakers WJ, Claes G, Terryn PJ, Belmans A, Hoekstra H, Nijs S. Reamer-Irrigator-Aspirator bone graft harvesting for treatment of segmental bone loss: analysis of defect volume as independent risk factor for failure. Eur J Trauma Emerg Surg. 2019;45(1):21-9. https://doi.org/10. 1007/s00068-017-0821-7.

5. Dehghan N, Schemitsch EH. Extended applications of the reamer-irrigator-aspirator (RIA) system. Injury. 2017;48(1):S47-51. https://doi.org/10. 1016/j.injury.2017.04.025. Epub 2017 Apr 29.

6. Davis RL, Taylor BC, Johnson N, Ferrel JR, Castaneda J. Retrograde versus antegrade femoral bone graft harvesting using the Reamer-IrrigatorAspirator. J Orthop Trauma. 2015;29(8):370-2. https://doi.org/10.1097/ BOT.0000000000000300.

7. Kanakaris NK, Morell D, Gudipati S, Britten S, Giannoudis PV. Reaming Irrigator Aspirator system: early experience of its multipurpose use. Injury. 2011;42(SUPPL. 4):S28-34. https://doi.org/10.1016/S0020-1383(11) 70009-2.

8. McCall TA, Brokaw DS, Jelen BA, et al. Treatment of large segmental bone defects with Reamer-Irrigator-Aspirator bone graft: technique and case 
series. Orthop Clin North Am. 2010;41(1):63-73. https://doi.org/10.1016/j. ocl.2009.08.002.

9. Han F, Peter L, Lau ETC, Thambiah J, Murphy D, Kagda FHY. Reamer Irrigator Aspirator bone graft harvesting: complications and outcomes in an Asian population. Injury. 2015;46(10):2042-51. https://doi.org/10.1016/j. injury.2015.07.027.

10. Stafford PR, Norris BL. Reamer-irrigator-aspirator bone graft and bi masquelet technique for segmental bone defect nonunions: a review of 25 cases. Injury. 2010;41(SUPPL. 2):S72-7. https://doi.org/10.1016/S00201383(10)70014-0.

11. Madison RD, Nowotarski PJ. The Reamer-Irrigator-Aspirator in nonunion surgery. Orthop Clin North Am. 2019;50(3):297-304. https://doi.org/10. 1016/j.ocl.2019.03.001.

12. Le Baron M, Vivona JP, Maman P, Volpi R, Flecher X. Can the Reamer/Irrigator/Aspirator System replace anterior iliac crest grafting when treating long bone nonunion? Orthop Traumatol Res. 2019;105(3):525-33.

13. Sagi HC, Young ML, Gerstenfeld L, Einhorn TA, Tornetta P. Qualitative and quantitative differences between bone graft obtained from the medullary canal (with a reamer/irrigator/aspirator) and the iliac crest of the same patient. J Bone Joint Surg (Am). 2012;94(23):2128-35. https://doi. org/10.2106/JBJS.L.00159.

14. El-Jawhari JJ, Ganguly P, Churchman S, Jones E, Giannoudis PV. The biological fitness of bone progenitor cells in Reamer/Irrigator/Aspirator waste. J Bone Joint Surg Am. 2019;101(23):2111-9. https://doi.org/10. 2106/JBJS.19.00133.

15. Belthur MV, Conway JD, Jindal G, Ranade A, Herzenberg JE. Bone graft harvest using a new intramedullary system. Clin Orthop Relat Res. 2008;466(12):2973-80. https://doi.org/10.1007/s11999-008-0538-3 Epub 2008 Oct 8 .

16. Schmitz N, Gehweiler D, Wähnert D, Zderic I, Grünwald L, Richards G, Gueorguiev B, Raschke M. Influence of the Reamer-Irrigator-Aspirator diameter on femoral bone strength and amount of harvested bone graft -a biomechanical cadaveric study. Injury. 2020;51(12):2846-50. https:// doi.org/10.1016/j.injury.2020.09.057.

17. Haubruck P, Ober J, Heller R, Miska M, Schmidmaier G, Tanner MC. Complications and risk management in the use of the reaming-irrigatoraspirator (RIA) system: RIA is a safe and reliable method in harvesting autologous bone graft. PLoS One. 2018;13(4): e0196051. https://doi.org/ 10.1371/journal.pone.0196051.

18. Marchand LS, Rothberg DL, Kubiak EN, Higgins TF. Is this autograft worth it?: the blood loss and transfusion ratesassociated with reamer irrigator aspirator bone graft harvest. J Orthop Trauma. 2017;31(4):205-9. https:// doi.org/10.1097/BOT.0000000000000811.

\section{Publisher's Note}

Springer Nature remains neutral with regard to jurisdictional claims in published maps and institutional affiliations.

Ready to submit your research? Choose BMC and benefit from:

- fast, convenient online submission

- thorough peer review by experienced researchers in your field

- rapid publication on acceptance

- support for research data, including large and complex data types

- gold Open Access which fosters wider collaboration and increased citations

- maximum visibility for your research: over 100M website views per year

At BMC, research is always in progress.

Learn more biomedcentral.com/submissions 